\title{
НАБЛИЖЕНА ЗАСТУПНА ЕЛЕКТРИЧНА СХЕМА СИНХРОННОГО ЯВНОПОЛЮСНОГО ГЕНЕРАТОРА ДЛЯ АНАЛІЗУ НАВАНТАЖУВАЛЬНИХ РЕЖИМІВ РОБОТИ АВТОНОМНИХ ВІТРО- ТА ГІДРОЕЛЕКТРИЧНИХ УСТАНОВОК
}

\author{
П.Ф. Васько, докт. техн. наук, \\ Інститут відновлюваної енергетики НАН України, \\ 02094, вул. Гната Хоткевича, 20А, м. Київ, Україна.
}

Синхронні явнополюсні генератори знаходять широке застосування в складі вітро- та гідроелектричних установок малої потужності. На сьогодні набуває актуальності задача застосування потужних автономних вітроелектричних установок з синхронними генераторами для накопичення частини генерованої ними енергї на гідроакумулювальних електростанціях. Розроблення раціональних схемо-технічних рімень реалізачї̈ даної технологї для багатоагрегатних вітроелектростанцій потребує аналізу навантажувальних режимів роботи всіх складових в широкому діапазоні робочих швидкостей вітру $і$ частоти обертання. Ефективне моделювання та проведення розрахункових досліджень перебігу електромеханічних прочесів в даних системах може бути реалізовано шляхом застосування заступних електричних схем генераторів та двигунів, проте для явнополюсного синхронного генератора неможливо побудувати точну заступну електричну схему для електрорушійної сили обмотки якоря. В рамках иъього дослідження розроблено наближену заступну електричну схему фази явнополюсного синхронного генератора та виконано оцінку можливих похибок результатів розрахунку параметрів навантажувального режиму схеми за різних значень частоти обертання ротора. Схема базується на послідовному ввімкненні активного опору обмотки якоря та індуктивних опорів розсіювання і поперекової реакиії якоря, а також індуктивного опору, зумовленого сумісною дією поперекової та повздовжньої реакцій якоря. Очікувані похибки визначення розрахункових параметрів напруги споживачів автономної системи електроживлення на основі вітро- та гідроелектричних установок з синхронними явнополюсними генераторами за використання розробленої заступної електричної схеми не перевищують 2,5\% по модулю та 1,5 електричних градусів по фазі для довільного значення частоти обертання ротора генератора в діапазоні 0,6..1,2 номінального значення. Застосування розробленої заступної електричної схеми явнополюсного синхронного генератора надає можливості проведення автоматизованих багатоваріантних розрахункових досліджень електромеханічних перехідних прочесів в системах електроживлення на основі вітро- та гідроелектричних установок з урахуванням пульсацій швидкості вітру, зміни витрат та напорів води, зміни навантаження. Бібл. 24, табл. 3, рис. 3.

Ключові слова: генератор синхронний явнополюсний, векторна діаграма, реакція якоря, схема заступна електрична.

\section{APPROXIMATE SUBSTITUTION ELECTRICAL EQUIVALENT CIRCUIT OF EXPLICIT POLE SYNCHRONOUS GENERATOR FOR ANALYSIS OF LOADING OPERATING MODES AUTONOMOUS WIND-ELECTRIC AND HYDROELECTRIC INSTALLATIONS}

P. Vasko, doctor of technical science

Institute of Renewable Energy of the National Academy of Sciences of Ukraine, 02094, 20A Hnata Khotkevycha St., Kyiv, Ukraine.

Synchronous generators with an explicit pole are widely used in wind and low-power hydropower plants. Today, the problem of using powerful autonomous wind power plants with synchronous generators to accumulate part of the energy generated by them at pumped hydro storage power station is becoming relevant. The development of rational circuit and technical solutions for the implementation of this technology for multi-unit wind-electric station requires analysis of the load modes of operation of all components in a wide range of operating wind speeds and rotor rotation speeds. Effective modeling and computational studies of electromechanical processes in these systems can be realized by using substitution electrical circuit of generators and motors, but for an explicit pole synchronous generator it is impossible to build an accurate electrical equivalent circuit for the electromotive force of the armature winding. In the framework of this study, an approximate electrical equivalent circuit diagram of the phase explicit pole synchronous generator was developed and an estimate of possible errors in the calculation of the parameters of the load mode of the circuit at different values of the rotor speed has been performed. The scheme is based on the sequential switching on of the active resistance of the armature winding and inductive resistances of scattering and lumbar reaction of the armature, as well as inductive resistance due to the combined action of the lumbar and longitudinal reactions of the armature. The expected errors in determining the calculated voltage parameters of consumers of autonomous power supply systems based on wind and hydroelectric installations with synchronous explicit pole generators using the developed electrical equivalent circuit do not exceed $2.5 \%$ modulus and 1.5 electric degrees per phase for arbitrary generator rotor speed. in the range of 0.6 ... 1.2 nominal value. The application of the developed electrical equivalent circuit of the explicit pole synchronous generator provides opportunities for

(С) П.Ф. Васько, 2020

Відновлювана енергетика. 2020. № 3 
automated multivariate calculation studies of electromechanical transients in power supply systems based on wind-electric and hydroelectric installations taking into account wind speed pulsations, changes in water flow discharge and water head, load changes. Ref. 24, tab. 3, fig. 3.

Keywords: synchronous explicit-pole generator, vector diagram, armature reaction, electrical equivalent circuit.

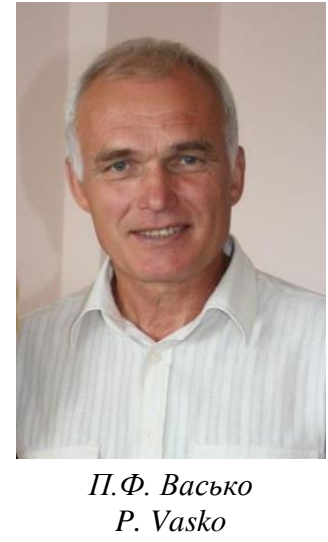

Відомості про автора: доктор технічних наук за спеціальністю «Перетворення відновлюваних видів енергії, завідувач відділом гідроенергетики Інституту відновлюваної енергетики НАНУ.

Освіта: Національний технічний університет України «Київський політехнічний інститут». Наукова сфера: альтернативна енергетика , енергозбереження, перетворення відновлюваних видів енергії, мала гідроенергетика.

Публікації: 252.

ORCID: 0000-0001-8807-7173

Контакти: тел./факс: +38-044-206-28-09 e-mail: hydro@ive.org.ua
Author information: doctor of technical sciences majoring in «Renewable Energy Transformation», Head of Hydropower Department of the Institute of Renewable Energy NAS of Ukraine.

Education: National Technical University of Ukraine «Kyiv Polytechnic Institute».

Research area: alternative energy, energy saving, conversion of renewable energy types and installations based on them, small hydropower.

Publications: 252.

ORCID: 0000-0001-8807-7173

Contacts: tel./fax: +38-044-206-28-09

e-mail: hydro@ive.org.ua
Вступ. Синхронні явнополюсні генератори знаходять широке застосування в складі вітро- та гідроелектричних установок малої потужності [1-3]. Використовуються конструкції генераторів 3 електромагнітним збудженням та збудженням від постійних магнітів. За потужності до декількох кіловат синхронна машина функціонує, в переважній більшості випадків, в режимі вентильного генератора $[4,5] \quad 3$ подальшим перетворенням електроенергії напівпровідниковими пристроями. За більшої потужності навантаження доцільно отримувати електроенергію змінного струму безпосередньо від синхронного генератора [3], особливо для систем водопостачання [1] 3 приводом гідронасосів від асинхронних електродвигунів 3 короткозамкненою обмоткою ротора, яким в пускових режимах властиве 5-7 кратне збільшення струму відносно номінального режиму навантаження [6,7].

На сьогодні набуває актуальності задача застосування потужних автономних вітроелектричних установок 3 синхронними генераторами для накопичення частини генерованої ними енергії на гідроакумулювальних електростанціях [8-11]. Розроблення раціональних схемо-технічних рішень реалізації даної технології для багатоагрегатних вітроелектростанцій потребує аналізу навантажувальних режимів роботи всіх складових в широкому діапазоні робочих швидкостей швидкості вітру і частоти обертання. Наявність стохастичної складової зміни швидкості вітру зумовлює значні коливання генерованої потужності i частоти обертання генератора, експериментальне підтвердження яких наведено в $[12,13]$. Аналізуються різні варіанти регулювання частоти для реалізації заряду гідроакумулювальних електростанцій від вітроелектричних установок [1416]. Ефективне моделювання та проведення розрахункових досліджень перебігу електромеханічних процесів в даних системах може бути реалізовано шляхом застосування заступних електричних схем генераторів та двигунів [17]. Проте для автономного явнополюсного синхронного генератора неможливо побудувати точну заступну електричну схему для електрорушійної сили (ЕРС) обмотки якоря $[18,19]$. Тому при аналізі потужних електроенергетичних систем використовують фіктивну ЕРС якоря, значення якої змінюється і залежить від режиму роботи генератора [20,21]. Даний підхід реалізується за припущень, що частота системи відома. Для аналізу автономних вітро- та гідроелектричних установок 3 явнополюсними синхронними генераторами (СГ) застосування такого припущення є неприйнятним, що зумовлює пошук нових підходів для розрахунку навантажувальних режимів роботи за змінних значень моменту і частоти обертання турбін.

Мета роботи полягає в розробленні наближеної заступної електричної схеми фази автономного явнополюсного СГ для заданого значення ЕРС обмотки якоря та в оцінці можливих похибок розрахунку параметрів навантажувального режиму схеми за різних значень частоти обертання ротора. 
Теоретичні положення. Подальше викладення матеріалу буде здійснено відповідно до основних положень теоретичних основ електротехніки для кіл змінного струму [22,23] та електричних машин [18,19] 3 використанням комплексних чисел за припущення про симетричність фаз генератора, лінії електропередачі та навантаження.

Представимо узагальнену заступну схему фази автономної системи електроживлення навантаження, як показано на рис.1, де позначено:

$\omega$ - частота обертання ротора генератора; $\dot{\mathrm{E}}_{\mathrm{G}}(i, \omega)$ комплексне значення ЕРС обмотки якоря явнополюсного СГ в залежності від струму обмотки збудження (i) та частоти обертання ротора $\omega$; $\dot{Z}_{\mathrm{G}}(\omega)$ - комплексне значення внутрішнього опору явнополюсного СГ за частоти обертання ротора $\omega$; I - комплексне значення струму генератора та еквівалентного навантаження; $\dot{Z}_{\mathrm{L}}(\omega), \quad \dot{Z}_{\mathrm{P}}(\omega)-$ комплексні значення опору лінії електропередачі та навантаження відповідно, включно 3 трансформаторними підстанціями за їх наявності, за частоти обертання ротора генератора $\omega ; \dot{\mathrm{U}}_{\mathrm{G}}, \dot{\mathrm{U}}_{\mathrm{P}}$ комплексні значення напруги на клемах генератора та навантаження.



Рис. 1. Узагальнена заступна електрична схема фази симетричної автономної системи електроживлення.

Fig. 1. Generalized substitution electrical circuit diagram electrical phase of symmetrical autonomous power supply system.

Введемо для подальшого застосування позначення комплексних значень опорів, струмів, напруг, та ЕРС схеми на рис.1 в наступному виді [22,23]:

$$
\begin{aligned}
& \dot{\mathrm{Z}}=\mathrm{R} \pm \mathrm{jX}=\operatorname{Re}(\dot{\mathrm{Z}}) \pm \mathrm{j} \operatorname{Im}(\dot{\mathrm{Z}})=|\dot{\mathrm{Z}}| \mathrm{e}^{\mathrm{j} \varphi}=\mathrm{Ze}^{\mathrm{j} \varphi}, \varphi=\operatorname{arctg}(\operatorname{Im}(\dot{\mathrm{Z}}) / \operatorname{Re}(\dot{\mathrm{Z}})), \\
& \dot{\mathrm{I}}=|\dot{\mathrm{I}}| \mathrm{e}^{\mathrm{j} \psi \mathrm{i}}=\mathrm{Ie}^{\mathrm{j} \psi \mathrm{i}}, \dot{\mathrm{U}}=|\dot{\mathrm{U}}| \mathrm{e}^{\mathrm{j} \psi \mathrm{u}}=\mathrm{U} \mathrm{e}^{\mathrm{j} \psi \mathrm{u}}, \dot{\mathrm{E}}=|\dot{\mathrm{E}}| \mathrm{e}^{\mathrm{j} \psi \mathrm{e}}=\mathrm{Ee}^{\mathrm{j} \psi \mathrm{e}}, \varphi=\psi_{\mathrm{u}}-\psi_{\mathrm{i}}, \dot{\mathrm{j}}^{2}=-1, \\
& \psi_{\mathrm{i}}=\operatorname{arctg}(\operatorname{Im}(\dot{\mathrm{I}}) / \operatorname{Re}(\dot{\mathrm{I}})), \psi_{\mathrm{u}}=\operatorname{arctg}(\operatorname{Im}(\dot{\mathrm{U}}) / \operatorname{Re}(\dot{\mathrm{U}})), \psi_{\mathrm{e}}=\operatorname{arctg}(\operatorname{Im}(\dot{\mathrm{E}}) / \operatorname{Re}(\dot{\mathrm{E}})),
\end{aligned}
$$


де $\operatorname{Re}(\dot{Z}), \operatorname{Im}(\dot{Z})$ - ідентифікатор дійсної та уявної складових комплексного числа $\dot{Z} ; \mathrm{R}, \mathrm{X}$ - активна та реактивна складові комплексного числа $\dot{Z}$ відповідно; $|\dot{Z}|, Z$ - модуль комплексного числа; $\varphi, \psi$ - аргументи відповідних комплексних чисел.

Визначення комплексного значення внутрішнього опору явнополюсного СГ за сталих значень частоти обертання та струму в обмотці збудження будемо здійснювати, відповідно до схеми на рис.1, за наступним виразом:

$$
\dot{\mathrm{Z}}_{\mathrm{G}}=\left(\dot{\mathrm{E}}_{\mathrm{G}}-\dot{\mathrm{U}}_{\mathrm{G}}\right) / \dot{\mathrm{I}} \text {. }
$$

Вихідне рівняння для ЕРС фази обмотки якоря явнополюсного СГ представимо, згідно 3 положеннями теорії двох реакцій $[18,19]$, наступним чином :

$$
\begin{gathered}
\dot{\mathrm{E}}_{\mathrm{G}}=\dot{\mathrm{U}}_{\mathrm{G}}+\dot{\mathrm{I}}_{\mathrm{a}}+\dot{\mathrm{j}} \dot{\mathrm{X}}_{\mathrm{a}}+\dot{\mathrm{U}}_{\mathrm{dq}}, \\
\dot{\mathrm{U}}_{\mathrm{dq}}=\dot{\mathrm{j}}_{\mathrm{q}} \mathrm{X}_{\mathrm{aq}}+\dot{\mathrm{j}}_{\mathrm{d}} \mathrm{X}_{\mathrm{ad}},
\end{gathered}
$$

де $\mathrm{R}_{\mathrm{a}}$ - активний опір обмотки статора; $\mathrm{X}_{\mathrm{a}}$ індуктивний опір обмотки статора, зумовлений потоком розсіювання; $\dot{U}_{\mathrm{dq}}$ - внутрішне падіння напруги в обмотці, зумовлене дією реакції якоря в повздовжній та поперековій осях генератора; $\dot{\mathrm{I}}_{\mathrm{q}}, \dot{\mathrm{I}}_{\mathrm{d}}$ - складові комплексного значення струму статора в поперековій та повздовжній осях генератора відповідно; $\mathrm{X}_{\mathrm{aq}}, \mathrm{X}_{\mathrm{ad}}$ - індуктивний опір обмотки статора, зумовлений потоком реакції якоря в поперековій та повздовжній осях генератора відповідно.

$$
\text { Після підстановки (3) в (2) отримуємо в }
$$

явному виді перші дві складові $\dot{Z}_{\mathrm{G}}$, що являють собою послідовне ввімкнення активного та індуктивного опорів обмотки якоря генератора:

$$
\dot{\mathrm{Z}}_{\mathrm{G}}=\mathrm{R}_{\mathrm{a}}+\mathrm{jX}+\dot{\mathrm{U}}_{\mathrm{dq}} / \dot{\mathrm{I}} \text {. }
$$

Визначення решти складових $\dot{Z}_{\mathrm{G}}$ в (4), зумовлених реакцією якоря в обох осях, будемо здійснювати 3 використанням векторного представлення рівняння (3) на площині комплексних чисел $[18,19]$ за умови $\psi_{\text {up }}=0$, як показано на рис. 2 , де позначено: $\mathrm{d}, \mathrm{q}$ - повздовжня та поперекова осі генератора відповідно; $\varphi_{\mathrm{G}}$ - кут зсуву по фазі між напругою та струмом генератора; $\beta$ - кут зсуву по фазі між ЕРС та струмом генератора; $\theta$ кут зсуву по фазі між ЕРС та напругою генератора; а також:

$$
\dot{\mathrm{I}}_{\mathrm{d}}=\dot{\mathrm{I}} \sin \beta, \quad \dot{\mathrm{I}}_{\mathrm{q}}=\dot{\mathrm{I}} \cos \beta, \quad \theta=\beta-\varphi_{\mathrm{G}} .
$$

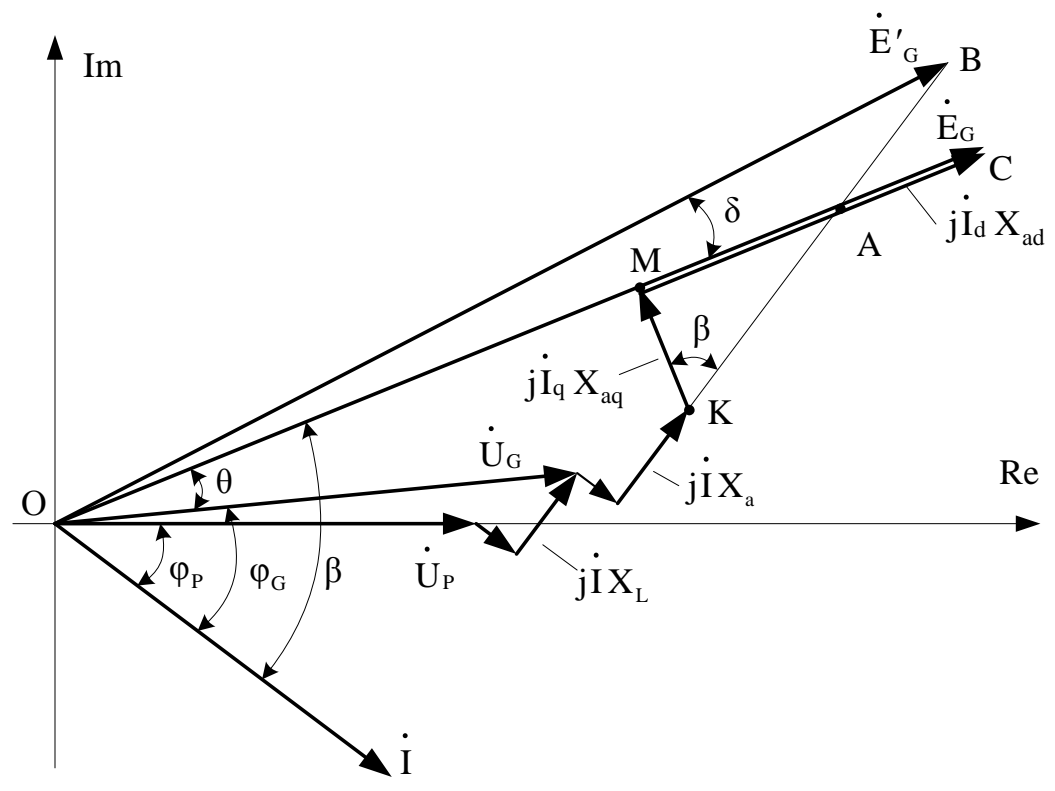

Рис. 2. Векторна діаграма напруг системи електроживлення на основі явнополюсного СГ.

Fig. 2. Vector voltage diagram of the power supply system based on explicit pole synchronous generator. 
Побудова векторної діаграми складової $\dot{\mathrm{U}}_{\mathrm{dq}}$ на рис.2 виконується 3 використанням розрахункових складових струму $\dot{\mathrm{I}}_{\mathrm{d}}$ та $\dot{\mathrm{I}}_{\mathrm{q}}$ (4). Тому для визначення елементів схеми заміщення на цій дільниці необхідно розрахувати відповідні падіння напруги через величину струму якоря I. Для цього виконаємо додаткові геометричні побудови, як показано на рис.2, де подовжено відрізок $\mathrm{j} \mathrm{IX}_{\mathrm{a}}$, який перпендикулярний вектору струму I , до перетину $з$ вектором ОС в точці А. Після чого представимо $\dot{\mathrm{U}}_{\mathrm{dq}}$ в наступному виді:

$$
\dot{\mathrm{U}}_{\mathrm{dq}}=\dot{\mathrm{U}}_{\mathrm{KA}}+\dot{\mathrm{U}}_{\mathrm{AC}} \text {. }
$$

В даному випадку складова $\dot{U}_{\mathrm{KA}, ~}$ урахуванням позначень на рис. 2 та співвідношень (6), дорівнює:

$$
\dot{\mathrm{U}}_{\mathrm{KA}}=\dot{\mathrm{j}} \dot{\mathrm{X}}_{\mathrm{aq}} .
$$

Після підстановки (7),(8) в (5) отримуємо ще один параметр схеми заміщення, а саме опір $\mathrm{X}_{\mathrm{aq}}$, який повинен бути ввімкненим послідовно $3 \mathrm{R}_{\mathrm{a}}$ та $\mathrm{X}_{\mathrm{a}}$ :

$$
\dot{\mathrm{Z}}_{\mathrm{G}}=\mathrm{R}_{\mathrm{a}}+\mathrm{j} \mathrm{X}_{\mathrm{a}}++\mathrm{j} \mathrm{X}_{\mathrm{aq}}+\dot{\mathrm{U}}_{\mathrm{AC}} / \dot{\mathrm{I}} \text {. }
$$

Результати побудови векторної діаграми також показують, що значення кута $\beta$ залежить тільки від параметрів обмотки якоря $\mathrm{R}_{\mathrm{a}}, \mathrm{X}_{\mathrm{a}}, \mathrm{X}_{\mathrm{aq}}$ та кута зсуву фаз від навантаження на клемах генератора, що можна записати в наступній формі:

$$
\beta=\arcsin \frac{\mathrm{X}_{\mathrm{a}}+\mathrm{X}_{\mathrm{aq}}+\operatorname{Im}\left(\dot{\mathrm{Z}}_{\mathrm{L}}+\dot{\mathrm{Z}}_{\mathrm{P}}\right)}{\left|\mathrm{R}_{\mathrm{a}}+\mathrm{j} \mathrm{X}_{\mathrm{a}}+\mathrm{j} \mathrm{X}_{\mathrm{aq}}+\dot{\mathrm{Z}}_{\mathrm{L}}+\dot{\mathrm{Z}}_{\mathrm{P}}\right|} .
$$

Відповідно, вираз для визначення кута $\theta$ приймає вид:

$$
\theta=\beta-\varphi_{\mathrm{G}}=\beta-\arcsin \frac{\operatorname{Im}\left(\dot{\mathrm{Z}}_{\mathrm{L}}+\dot{\mathrm{Z}}_{\mathrm{P}}\right)}{\left|\dot{\mathrm{Z}}_{\mathrm{L}}+\dot{\mathrm{Z}}_{\mathrm{P}}\right|} .
$$

Далі розглянемо визначення останньої складової внутрішнього опору в (9). Для цього розрахуємо модуль $\dot{\mathrm{U}}_{\mathrm{AC}}$ в залежності від модуля струму якоря з урахуванням (4) та (6):

$$
\left|\dot{\mathrm{U}}_{\mathrm{AC}}\right|=\left|\dot{\mathrm{I}}_{\mathrm{d}} \mathrm{X}_{\mathrm{ad}}-\dot{\mathrm{I}}_{\mathrm{aq}} \sin \beta\right|=\mathrm{I}\left(\mathrm{X}_{\mathrm{ad}}-\mathrm{X}_{\mathrm{aq}}\right) \sin \beta \text {. }
$$

Отриманий результат засвідчує пропорційну залежність модуля $\left|\dot{U}_{\mathrm{AC}}\right|$ від модуля струму якоря, але їх розташування на комплексній площині (рис.2) не $\epsilon$ взаємоперпендикулярним, що унеможливлює коректне визначення четвертої складової внутрішнього опору генератора по (9). Проте досягти взаємоперпендикулярного розташування комплексних величин $\dot{\mathrm{U}}_{\mathrm{AC}}$ та $\dot{\mathrm{I}}$ можливо в результаті повороту $\dot{\mathrm{E}}_{\mathrm{G}}$ на кут $\delta$ до перетину з продовженням лінії КА в точці В, як показано на рис.2. Фізичний зміст такої процедури полягає в заміні $\dot{\mathrm{E}}_{\mathrm{G}}$ на розрахункову величину $\dot{\mathrm{E}}_{\mathrm{G}}{ }_{\mathrm{G}}$, рівну по модулю, але зі зміною аргументу на величину $\delta$ :

$$
\dot{\mathrm{E}}_{\mathrm{G}}^{\prime}=\dot{\mathrm{E}}_{\mathrm{G}} \mathrm{e}^{\mathrm{j} \delta} .
$$

В цьому випадку рівняння (9) трансформується, 3 урахуванням (12)-(13), до наступного наближеного:

$$
\begin{gathered}
\dot{\mathrm{Z}}_{\mathrm{G}} \approx \mathrm{R}_{\mathrm{a}}+\mathrm{j} \mathrm{X}_{\mathrm{a}}++\mathrm{j} \mathrm{X}_{\mathrm{aq}}+\mathrm{j}\left(\mathrm{X}_{\mathrm{ad}}-\mathrm{X}_{\mathrm{aq}}\right) \sin \beta, \\
\text { за умови } \dot{\mathrm{E}}_{{ }_{\mathrm{G}}}^{\prime}=\dot{\mathrm{E}}_{\mathrm{G}} \mathrm{e}^{\mathrm{j} \delta} .
\end{gathered}
$$

Похибка в (14) зумовлена різною довжиною відрізків $\mathrm{AC}$ та $\mathrm{AB}$ на векторній діаграмі:

$$
|\overline{\mathrm{AC}}| \neq|\overline{\mathrm{AB}}| \text {. }
$$

Для урахування впливу частоти обертання на комплексні значення опорів введемо співвідношення [22,23]:

$$
\dot{\mathrm{Z}}(\omega)=\mathrm{R}+\mathrm{jX} \omega \text {. }
$$

3 урахуванням (14), (16) узагальнена заступна схема СГ на рис.1 може бути деталізована до наступної наближеної (рис.3): 


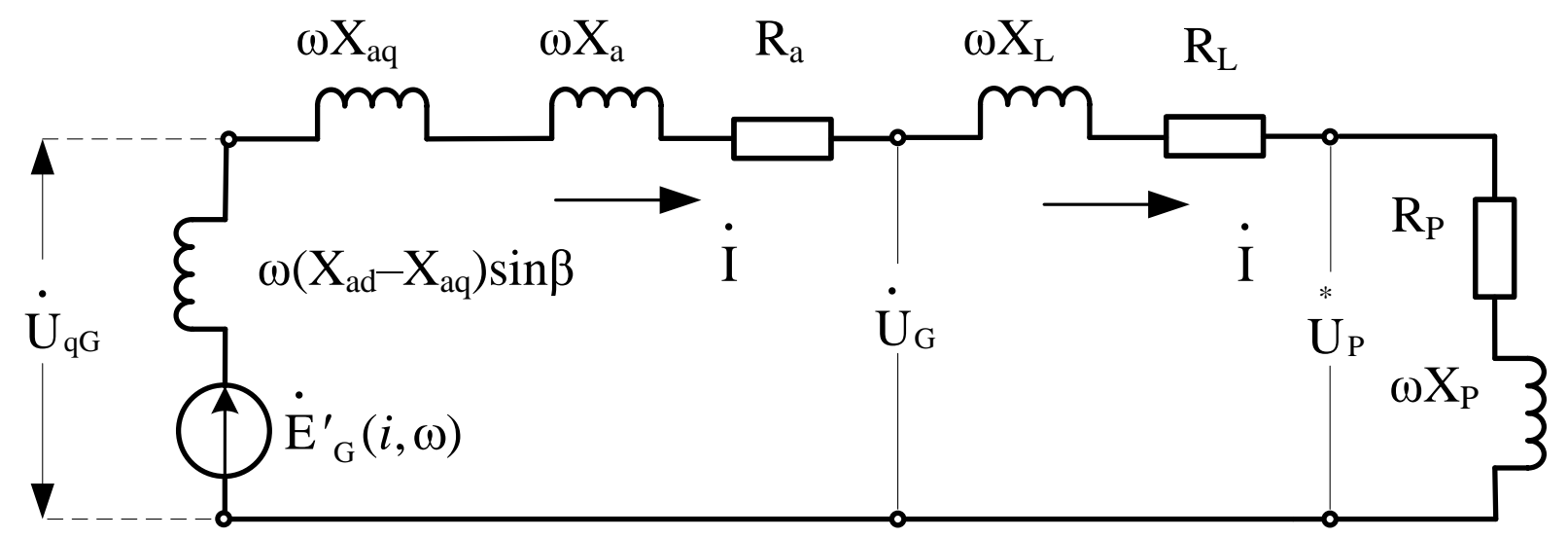

Рис. 3. Заступна електрична схема фази симетричної автономної системи електроживлення на основі явнополюсного СГ.

Fig. 3. Electrical substitution circuit diagram of a symmetrical autonomous power supply system based on explicit pole synchronous generator.

Обчислення необхідного значення модуля ЕРС в заступній схемі для різних значень частот обертання $\left(\mathrm{E}_{\mathrm{G}}(i, \omega)\right)$ здійснюється з використанням параметрів схеми наступним чином:

$$
\begin{aligned}
& E_{G}(i, \omega)=I\left(X_{a d}-X_{a q}\right) \omega \sin \beta_{\omega}+I\left(X_{a q}+X_{a}\right) \omega \sin \beta_{\omega}+I_{a} \cos \beta_{\omega}+U_{G_{\omega}} \cos \theta_{\omega}= \\
& =I\left[\left(X_{d} \omega \sin \beta_{\omega}+R_{a} \cos \beta_{\omega}\right)+\sqrt{\left(\left(R_{P}+R_{L}\right)^{2}+\left(X_{P}+X_{L}\right)^{2} \omega^{2}\right)} \cos \theta_{\omega}\right]
\end{aligned}
$$

Значення $\beta_{\omega}, \theta_{\omega}$ в (17) визначаються по (10), (11) з урахуванням (16):

$$
\begin{gathered}
\beta_{\omega}=\arcsin \frac{\left(X_{a}+X_{a q}+X_{L}+X_{P}\right) \omega}{\left|R_{a}+R_{L}+R_{P}+j\left(X_{a}+X_{a q}+X_{L}+X_{P}\right) \omega\right|}, \\
\theta_{\omega}=\beta_{\omega}-\varphi_{G \omega}=\beta_{\omega}-\arcsin \frac{\left(X_{L}+X_{P}\right) \omega}{\left|R_{L}+R_{P}+j\left(X_{L}+X_{P}\right) \omega\right|} .
\end{gathered}
$$

Таким чином, розрахункові дослідження навантажувальних режимів роботи генератора можуть бути реалізовані 3 використанням параметрів отриманої заступної схеми (14) та кута $\delta$, точне визначення якого потребує побудови векторної діаграми. Проте його наближене значення в функції частоти обертання $\left(\delta_{\omega}\right)$ може бути розраховане у відповідності до векторної діаграми за виразом:

$$
\delta_{\omega} \approx \operatorname{arctg}\left(\frac{\mathrm{I}\left(\mathrm{X}_{\mathrm{ad}}-\mathrm{X}_{\mathrm{aq}}\right) \omega \cos \beta_{\omega}}{\mathrm{E}_{\mathrm{G}}(\mathrm{i}, \omega)}\right) .
$$

Процедура визначення $\delta_{\omega}$ по (20) має перевагу (за прийнятної похибки) в разі необхідності проведення багатоваріантних розрахункових досліджень динаміки навантажувальних режимів роботи системи електроживлення під впливом збурень [24].

Остаточний вираз для визначення комплексної величини ЕРС (13) заступної електричної схеми генератора для різної частоти обертання ротора ( $\left.\dot{\mathrm{E}}_{\mathrm{G}}^{\prime}(i, \omega)\right)$ набуває, 3 урахуванням (17)-(20), наступного виду:

$$
\begin{gathered}
\dot{\mathrm{E}}_{\mathrm{G}}^{\prime}(i, \omega)=\mathrm{E}_{\mathrm{G}}(\mathrm{i}, \omega) \mathrm{e}^{\mathrm{i} \psi \omega \omega}, \\
\psi_{\mathrm{e} \omega}=\theta_{\omega}+\delta_{\omega}+\varphi_{\mathrm{G} \omega}-\varphi_{\mathrm{P} \omega}+\psi_{\mathrm{uP} \omega},
\end{gathered}
$$

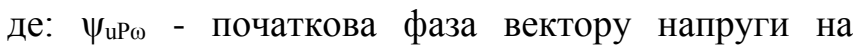
навантаженні ( $\dot{\mathrm{U}}_{\mathrm{P} \omega}$ ), яка для переважної більшості практичних задач може мати нульове значення: 
$\psi_{\text {uР }}=0$ (наведена умова застосовувалась при побудові векторної діаграми на рис.2).

За результатами розрахунку заступної схеми визначаються комплексні значення струму, падіння напруги на елементах та значення характерних кутів, зокрема $\beta_{\omega}, \quad \theta_{\omega}$

$$
\beta_{\omega}=\psi_{\text {uq } \omega}-\psi_{\text {i } \omega}, \theta_{\omega}=\psi_{\text {uq } \omega}-\psi_{\text {uG } \omega},
$$

де: $\psi_{\mathrm{uq} \omega}, \psi_{\mathrm{i \omega}}, \psi_{\mathrm{uG} \omega}, \psi_{\text {еш }}$ - аргументи відповідних комплексних величин, позначених на рис.3.

Аналіз результатів. У відповідності до мети роботи виконаємо оцінку можливих похибок розрахунку параметрів навантажувального режиму роботи явнополюсного СГ за розробленою наближеною заступною схемою для різних значень частоти обертання ротора.

Розрахункові дослідження похибок будемо здійснювати у системі відносних одиницях $[18,19]$, де базові значення розрахункових параметрів відповідають номінальному режиму роботи схеми:

$$
\begin{aligned}
& \omega_{\text {nom }}=1 \text { в.о., } \quad \mathrm{I}_{\text {nom }}=1 \text { в.о., } \\
& \mathrm{U}_{\text {Pnom }}=1 \text { в.0., } \mathrm{Z}_{\text {Pnom }}=1 \text { в.0.. }
\end{aligned}
$$

За умов (23) параметри схеми (рис.3) для автономних систем електроживлення представимо наступними характерними кількісними значеннями у відносних одиницях:

$$
\begin{gathered}
\dot{\mathrm{Z}}_{\mathrm{P}}=0.8+\mathrm{j} 0.6, \dot{\mathrm{Z}}_{\mathrm{L}}=0.04+\mathrm{j} 0.15, \mathrm{X}_{\mathrm{aq}}=0.6, \\
\mathrm{X}_{\mathrm{ad}}=0.9, \mathrm{X}_{\mathrm{a}}=0.12, \mathrm{R}_{\mathrm{a}}=0.04,
\end{gathered}
$$

а зміну частоти обертання ротора генератора рядом дискретних значень в діапазоні імовірної зміни частоти обертання вітро- та гідротурбін в навантажувальних режимах роботи:

$$
\omega=(0.6,0.8,1.0,1.2) \omega_{\text {nom }} .
$$

Обчислення похибок будемо виконувати за умови стабілізації номінального значення струму навантаження, коли похибка визначення додаткового кута $\delta_{\omega}$ по (20) $є$ найбільшою:

$$
\mathrm{I}=\mathrm{I}_{\text {nom }}=\text { const. }
$$

Оцінку похибок здійснимо за результатами розрахунку параметрів системи електроживлення, отриманих шляхом застосування векторної діаграми та розробленої заступної схеми генератора. Результати розрахунків наведені в табл.1, табл. 2.

Таблиця 1. Параметри системи електроживлення, отримані в результаті побудови векторної діаграми.

Table 1. Power system parameters obtained as a result of constructing a vector diagram.

\begin{tabular}{|c|c|c|c|c|c|c|c|}
\hline $\begin{array}{c}\omega, \\
\text { в.о. }\end{array}$ & $\begin{array}{c}\text { Е, } \\
\text { в.о. }\end{array}$ & $\begin{array}{c}\theta, \\
\text { град. }\end{array}$ & $\begin{array}{c}\varphi_{\mathrm{p}}, \\
\text { град. }\end{array}$ & $\begin{array}{c}\varphi_{\mathrm{G}}, \\
\text { град. }\end{array}$ & $\begin{array}{c}\delta, \\
\text { град. }\end{array}$ & $\begin{array}{c}\beta, \\
\text { град. }\end{array}$ & $\begin{array}{c}\dot{\mathrm{U}}_{\mathrm{P}}, \\
\text { в.о. }\end{array}$ \\
\hline 0.6 & 1.373 & 16.89 & 24.23 & 28.18 & 5.29 & 45.07 & $0.877 \mathrm{e}^{\mathrm{j} 0}$ \\
\hline 0.8 & 1,66 & 17,65 & 30.96 & 35,54 & 4.95 & 53,19 & $0.933 \mathrm{e}^{\mathrm{j} 0}$ \\
\hline 1.0 & 1.97 & 17.33 & 36.87 & 41.76 & 4.47 & 59.09 & $1.0 \mathrm{e}^{\mathrm{j} 0}$ \\
\hline 1.2 & 2.294 & 16,51 & 41.99 & 46.98 & 4.0 & 63.49 & $1.076 \mathrm{e}^{\mathrm{j} 0}$ \\
\hline
\end{tabular}


Таблиця 2. Параметри системи електроживлення розраховані за заступною електричною схемою.

Table 2. The parameters of the power supply system are calculated according to the electrical substitution circuit.

\begin{tabular}{|c|c|c|c|c|c|c|c|}
\hline $\begin{array}{c}\omega, \\
\text { в.о. }\end{array}$ & $\begin{array}{c}\dot{\mathrm{E}}_{\mathrm{G}}^{\prime}, \\
\text { в.о. }\end{array}$ & $\begin{array}{c}\dot{\mathrm{I}}, \\
\text { в.о. }\end{array}$ & $\begin{array}{c}\dot{\mathrm{U}}_{\mathrm{qG}}, \\
\text { в.о. }\end{array}$ & $\begin{array}{c}\dot{\mathrm{U}}_{\mathrm{G}}, \\
\text { в.о. }\end{array}$ & $\begin{array}{c}\dot{\mathrm{U}}_{\mathrm{P}}, \\
\text { в.о. }\end{array}$ & $\begin{array}{c}\theta, \\
\text { град. }\end{array}$ & $\begin{array}{c}\beta, \\
\text { град. }\end{array}$ \\
\hline 0.6 & $1.373 \mathrm{e}^{\mathrm{j} 26.13}$ & $1.025 \mathrm{e}^{\mathrm{j}-22.79}$ & $1.277 \mathrm{e}^{\mathrm{j} 23.28}$ & $0.997 \mathrm{e}^{\mathrm{j} 5.39}$ & $0.899 \mathrm{e}^{\mathrm{j} 1.44}$ & 17.89 & 46.07 \\
\hline 0.8 & $1.66 \mathrm{e}^{\mathrm{j} 27.18}$ & $1.02 \mathrm{e}^{\mathrm{j}-30.07}$ & $1.5 \mathrm{e}^{\mathrm{j} 23.12}$ & $1.053 \mathrm{e}^{\mathrm{j} 5.47}$ & $0.952 \mathrm{e}^{\mathrm{j} 0.89}$ & 17,65 & 53,19 \\
\hline 1.0 & $1.97 \mathrm{e}^{\mathrm{j} 26.69}$ & $1.016 \mathrm{e}^{\mathrm{j}-36.31}$ & $1.74 \mathrm{e}^{\mathrm{j} 22.78}$ & $1.144 \mathrm{e}^{\mathrm{j} 5.45}$ & $1.016 \mathrm{e}^{\mathrm{j} 0.56}$ & 17.33 & 59.09 \\
\hline 1.2 & $2,294 \mathrm{e}^{\mathrm{j} 25.5}$ & $1.013 \mathrm{e}^{\mathrm{j}-41.63}$ & $1.997 \mathrm{e}^{\mathrm{j} 21.86}$ & $1.247 \mathrm{e}^{\mathrm{j} 5.34}$ & $1.09 \mathrm{e}^{\mathrm{j} 0.36}$ & 16,52 & 63.49 \\
\hline
\end{tabular}

Похибки визначення модуля та аргументу комплексного значення напруги на навантаженні системи електроживлення за використання розробленої наближеної заступної електричної схеми явнополюсного СГ, а також похибки визначення характерних кутів генератора $\theta$ та $\beta$ наведені в табл.3 i розраховувались за даними табл. 1 , табл. 2 наступним чином:

$$
\Delta \alpha=\frac{100\left(\alpha-\alpha^{\prime}\right)}{\alpha}, \Delta \psi_{\alpha}=\psi_{\alpha}-\psi_{\alpha}^{\prime},
$$

де: $\alpha, \alpha^{\prime}$ - результати розрахунку модуля комплексного показника по векторній діаграмі та наближеній заступній схемі відповідно; $\psi_{\alpha}, \psi_{\alpha}^{\prime}{ }^{\prime}$ результати розрахунку аргумента комплексного показника по векторній діаграмі та наближеній заступній схемі відповідно.

Таблиця 3. Похибки параметрів системи електроживлення розрахованих за заступною електричною схемою.

Table 3. Errors of power supply system parameters calculated according to the electrical substitution circuit.

\begin{tabular}{|c|c|c|c|c|}
\hline$\omega$, в.о. & $\Delta \mathrm{U}_{\text {Р }} \%$ & $\Delta \psi_{\text {uр, град. }}$ & $\Delta \theta$, град. & $\Delta \beta$, град \\
\hline 0.6 & -2.5 & -1.44 & -1.00 & -1.00 \\
\hline 0.8 & $-2,0$ & -0.89 & 0.00 & 0.00 \\
\hline 1.0 & -1.6 & -0.56 & 0.00 & 0.00 \\
\hline 1.2 & -1.3 & -0.36 & -0.01 & 0.00 \\
\hline
\end{tabular}

Отримані похибки розрахункових параметрів навантажувальних режимів роботи автономної системи електроживлення за використання розробленої заступної схеми явнополюсного СГ засвідчують прийнятну точність результатів в широкому діапазоні зміни частоти обертання ротора генератора. 
Висновки. 1. Розроблено наближену заступну електричну схему фази явнополюсного синхронного генератора в квазістаціонарних електромагнітних режимах роботи за різної частоти обертання ротора. Схема базується на послідовному ввімкненні активного опору обмотки якоря та індуктивних опорів розсіювання i поперекової реакції якоря, а також індуктивного опору, зумовленого сумісною дією поперекової та повздовжньої реакцій якоря.

\section{2. Очікувані похибки}

визначення розрахункових параметрів напруги споживачів автономної системи електроживлення на основі вітро- та гідроелектричних установок 3 синхронними явнополюсними генераторами за використання розробленої заступної електричної схеми СГ не перевищують 2,5\% по модулю та 1,5 електричних градусів по фазі для довільного значення частоти обертання ротора генератора в діапазоні 0,6...1,2 номінального значення.

3. Застосування розробленої заступної електричної схеми явнополюсного СГ надає можливості проведення автоматизованих багатоваріантних розрахункових досліджень електромеханічних перехідних процесів в системах електроживлення на основі вітро- та гідроелектричних установок 3 урахуванням пульсацій швидкості вітру, зміни витрат та напорів води, зміни навантаження.

1. Харитонов В.П. Автономные ветроэлектрические установки. М. ГНУ ВИЭСХ. 2006. 280 с.

2. Дзензерский В.А., Тарасов С.В., Костюков И.Ю. Ветроустановки малой мощности. Киев. Наукова думка. 2011. $591 \mathrm{c}$.

3. Елистратов В.В. Гидроэлектростанции малой мощности. Учеб. пособие. СПб. Изд-во Политехн. ун-та. 2005. $432 \mathrm{c}$.

4. Буm Д.А. Бесконтактные электрические машины. М. Высшая школа. 1990. 416 с.

5. Брускин Д.Э. Электрические машины и микромашины. М. Высшая школа. 1990. 528 с.

6. Кравчик А.Э., Шлаф М.М., Афонин В.И. Асинхронные двигатели серии 4А. Справочник. М. Энергоиздат. 1982. $504 \mathrm{c}$.

7. Копылов И.П., Клокова К.К. Справочник по электрическим машинам. В 2 т. Т.1. М. Энергоатомиздат. 1988. $456 \mathrm{c}$.
8. Merino J., Veganzones C., Jose A.S.., Martinez S., Platero CA. Power System Stability of a Small Sized Isolated Network Supplied by a Combined Wind-Pumped Storage Generation System: A Case Study in the Canary Islands. Energies. 2012. № 7. Pp. 2351-2369.

https://doi.org/10.3390/en5072351.

9. Frydrychowicz-Jastrzębska G. El Hierro Renewable Energy Hybrid System: A Tough Compromise. Energies. 2018. № 11(10). P. 2812.

https://doi.org/10.3390/en11102812.

10. Latorre F.G., Quintana J.J., Nuez I. Technical and economic evaluation of the integration of a wind-hydro system in El Hierro island. Renewable Energy. 2019. Vol. 134. Pp. 186-193.

https://doi.org/10.1016/j.renene.2018.11.047

11. Vasko P., Verbovij A., Moroz A., Pazych S., Ibragimova M., Sahno L. Concept of Accumulation of Energy from Photovoltaic and Wind Power Plants by Means of Seawater Pumped Hydroelectric Energy Storage. 2019 IEEE 6th International Conference on Energy Smart Systems (2019 IEEE ESS). April 17-19. 2019. Kyiv. Ukraine. Pp. 188-191. https://doi.org/10.1109/ESS.2019.8764167.

12. Васько В.П., Васько П.Ф. Динамика нагрузочных режимов работы ветроэлектрической установки, обусловленная порывами ветра. Вісник Донбаської державної академії будівництва i архітектури. 3б. наук. праць. 2001. № 4 (29). С. 140-144.

13. Васько П.Ф., Васько В.П., Даниленко О.І., Долюк В.В. Експериментальні дослідження режимів генерування та споживання реактивної потужності серійною вітроелектричною установкою 3 асинхронним генератором. Відновлювана енергетика. 2008. № 1. C. 34-38.

14. Martínez-Lucas G., Sarasúa J.I., SánchezFernández J.Á. Frequency Regulationof a Hybrid WindHydro Power Plant in an Isolated Power System. Energies. 2018. № 1.239 p.

15. Sarasúa J.I., Martínez-Lucas G., Platero C.A., Sánchez-Fernández J.Á. Dual Frequency Regulation in Pumping Modein a Wind-Hydro Isolated System. Energies. 2018. № 11. 2865 p. https://doi.org/10.3390/en11112865.

16. Sarasúa J.I., Martínez-Lucas G., Lafoz M. Analysis of alternative frequency control schemes for increasing renewable energy penetration in El Hierro Island power system. International Journal of Electrical Power \& Energy Systems. 2019. Vol. 113. Pp. 807-823. https://doi.org/10.1016/j.ijepes.2019.06.008.

17. Брыль А.А., Васько В.П., Васько П.Ф., Соловьев П.Б. Математическое моделирование нестационарных электромеханических процессов гидроэлектрических агрегатов малых ГЭС с различными типами генераторов 
при параллельной работе с электросистемой. Альтернативная энергетика и экология. 2013. №3. С. 143-150.

18. Вольдек А.И. Электрические машины. Л. Энергия. 1974. $840 \mathrm{c.}$

19. Иванов-Смоленский А.В. Электрические машины. М. Энергия. 1980. 928 с.

20. Веников B.A. Переходные электромеханические процессы в электрических системах. М. Высшая школа. 1985. $536 \mathrm{c.}$

21. Куликов Ю.А. Переходные процессы в электрических системах. Новосибирск. Изд-во НГТУ. 2006. 284 c.

22. Бессонов Л.А. Теоретические основы электротехники. Электрические цепи: Учеб. для электротехн. энерг. припоростроит. спец. вузов 9 изд.. перераб. и доп. М. Высш. шк. 1996. 638 с.

23. Маляр B.C. Теоретичні основи електротехніки. Електричні кола. навч. посібник. Львів. Видавництво Львівська політехніка. 2012. 312 с.

24. Васько П.Ф., Пазич С.T. Моделювання динаміки навантажувальних режимів роботи гідронасосної станції з електроприводом за живлення від вітроелектричної установки з синхронним генератором. Відновлювана енергетика. 2020. № 1. С. 61-73. https://doi.org/10.36296/1819-8058.2020.1(60).61-73.

\section{REFERENCE}

1. Haritonov V.P. Avtonomnyie vetroelektricheskie ustanovki. [Autonomous wind power plants]. Moscow. 2006. 280 p. [in Russian].

2. Dzenzerskiy V.A., Tarasov S.V., Kostyukov I.U. Vetroustanovki maloy moschnosti. [Low power wind turbines]. Kyiv. Naukova dumka. 2011. 591 p. [in Russian].

3. Elistratov V.V. Gidroelektrostantsii maloy moschnosti. [Low power hydroelectric power stations]. Textbook allowance. Publisher. Politechnic university. 2005. 432 p. [in Russian].

4. But D.A. Beskontaktnyie elektricheskie mashinyi. [Contactless electric machines]. Moscow. High school. 1990. 432 p. [in Russian].

5. Bruskin D.E. Elektricheskie mashinyi i mikromashinyi. [Electric machine and micromachines]. Moscow. High school. 1990. 528 p. [in Russian].

6. Kravchik A.E., Shlaf M.M., Afonin V.I. Asinhronnyie dvigateli serii 4A. [Series Induction Motors 4A]. Reference. Moscow. Energoizdat. 1982. 504 p. [in Russian].

7. Kopyilov I.P., Klokova K.K. Spravochnik po elektricheskim mashinam v 2 t. [Electric Machine Reference in 2 vol.]. Vol. 1. Moscow. Energoatomizdat. 1988. 456 p. [in Russian].

8. Merino J., Veganzones C., Jose A.S.., Martinez S., Platero $C A$. Power System Stability of a Small Sized Isolated Network Supplied by a Combined Wind-Pumped Storage Generation System: A Case Study in the Canary Islands. Energies. 2012. № 7. Pp. 2351-2369.

https://doi.org/10.3390/en5072351. [in English].

9. Frydrychowicz-Jastrzębska G. El Hierro Renewable Energy Hybrid System: A Tough Compromise. Energies. 2018. № 11(10). P. 2812. https://doi.org/10.3390/en11102812. [in English].

10. Latorre F.G., Quintana J.J., Nuez I. Technical and economic evaluation of the integration of a wind-hydro system in El Hierro island. Renewable Energy. 2019. Vol. 134. Pp. 186-193. https://doi.org/10.1016/j.renene.2018.11.047. [in English].

11. Vasko P., Verbovij A., Moroz A., Pazych S., Ibragimova M., Sahno L. Concept of Accumulation of Energy from Photovoltaic and Wind Power Plants by Means of Seawater Pumped Hydroelectric Energy Storage. 2019 IEEE 6th International Conference on Energy Smart Systems (2019 IEEE ESS). April 17-19. 2019. Kyiv. Ukraine. Pp. 188-191. https://doi.org/10.1109/ESS.2019.8764167. [in English].

12. Vasko, V.P., Vasko P.F. Dinamika nagruzochnyih rezhimov rabotyi vetroelektricheskoy ustanovki, obuslovlennaya poryivami vetra. [Dynamics of loading modes of the wind-electric installation, caused by gust of wind]. Bulletin of the Donbas State Academy of Civil Engineering and Architecture. Collection of scientific work. 2001. № 4(29). Pp. 140-144. [in Ukrainian].

13. Vasko P.F., Vasko V.P., Danylenko O.I., Doliuk V.V. Eksperymentalni doslidzhennia rezhymiv heneruvannia ta spozhyvannia reaktyvnoi potuzhnosti seriinoiu vitroelektrychnoiu ustanovkoiu z asynkhronnym heneratorom. [Experimental studies of the modes of generation and consumption of reactive power by a serial wind-driven installation with an asynchronous generator]. Renewable energy. 2008. № 1. Pp. 34-38. [in Ukrainian].

14. Martinez-Lucas G., Sarasua J.I., SanchezFernandez J.A. FrequencyRegulationof a Hybrid WindHydroPowerPlant in an Isolated Power System. Energies. 2018. № 1. 239 p. [in English].

15. Sarasua J.I., Martinez-Lucas G., Platero C.A., Sanchez-Fernandez J.A. Dual Frequency Regulation in Pumping Modein a Wind-Hydro Isolated System. Energies. 2018. № 11. 2865 p. https://doi.org/10.3390/en11112865. [in English].

16. Sarasua J.I., Martinez-Lucas G., Lafoz M. Analysis of alternative frequency control schemes for increasing renewable energy penetration in El Hierro Island power system. International Journal of Electrical Power \& 
Energy Systems. 2019. Vol. 113. Pp. 807-823. https://doi.org/10.1016/j.ijepes.2019.06.008. [in English].

17. Bryl A.O., Vasko V.P., Vasko P.F., Solovyov P.B. Matematičeskoe modelirovanie nestacionarnyh lektromehaničeskih processov gidroèlektričeskih agregatov malyh GES s razlicnymi tipami generatorov ri parallelnoj robote s elektrosistemoj. [Mathematical modeling of nonstationary electromechanical processes of hydroelectrical hardware for small hydro power stations with different types of generators at parallel functioning with electric system]. Alternative Energy and Ecology ISJAEE. 2013. № 3. Pp. 143-150. [in English].

18. Voldek A.I. Elektricheskie mashiny. [Electric machines]. 2 edition. L. Energy. 1974. 840 p. [in Russian].

19. Ivanov-Smolenskiy A.V. Elektricheskie mashinyi. [Electric machine]. Moscow. Energia. 1980. 928 p. [in Russian].

20. Venikov V.A. Perehodnyie elektromehanicheskie protsessyi $\mathrm{v}$ elektricheskih sistemah. [Transient electromechanical processes in electrical systems]. Moscow. High school. 195. 536 p. [in Russian].

21. Kulikov U.A. Perehodnyie protsessyi v elektricheskih sistemah. [Transients in electrical systems]. Novosibirsk. Publisher. NSTU. 2006. 284 p. [in Russian].
22. Bessonov L.A. Teoreticheskie osnovyi elektrotehniki. Elektricheskie tsepi. [Theoretical Foundations of Electrical Engineering. Electric circuits]. Ucheb. dlya elektrotehn., energ., priporostroit. spets. vuzov 9 izd., pererab. i dop. Moscow. High school. 1996. 638 p. [in Russian].

23. Malyar V.S. Teoretychni osnovy elektrotekhniky. Elektrychni kola. [Theoretical foundations of electrical engineering. Electric circuits]. Tutorial. Lviv. Lviv Polytechnic Publishing House. 2012. 312 p. [in Ukrainian].

24. Vasko P.F., Pazych S.T. Modeliuvannia dynamiky navantazhuvalnykh rezhymiv roboty hidronasosnoi stantsii z elektropryvodom za zhyvlennia vid vitroelektrychnoi ustanovky z synkhronnym heneratorom. [Modeling dynamics loading modes work of the hydro-pump station with the electric drive from power supply of the wind electric installation with the synchronous generator]. Vidnovluvana energetika. 2020. № $1 . \quad$ Pp .61-73. https://doi.org/10.36296/1819-8058.2020.1(60).61-73. [in Ukrainian]. 